\title{
Proceeding
}

Supplementary Issue: Spring Conferences of Sports Science. 15th Convention and Workshop of the International Network of Sport and Health Science, 5-8 June 2019. University of Las Palmas de Gran Canaria, Las Palmas de Gran Canaria, Spain.

\section{The movement: Complexity and reductionism, evidence in comparison}

\author{
FELICE DI DOMENICO , SIMONA FATTORE, TIZIANA D'ISANTO \\ University of Salerno, Italy
}

\begin{abstract}
The study of movement often contrasts complexity and reductionism. movement analysis helps to justify the reductionist model with data, aesthetic analysis contributes with the use of indicators, descriptors, weights. There is no evaluation model integrated with the contribution of perception to approach the evaluation with a more complex model. The aim of the study is to measure the motor skills of jumping, speed of execution, reaction times and agility, with a global view of the movement in addition to the whole of the individual acts to consider that the various destructured unit values are inseparable elements of a single set and which, according to the non-linear complexity, are mutually determined. The method is experimental research through the recruitment of data with questionnaires and surveys prepared with the Google Forms platform and the evaluation of motor gestures with technological tools: Optojump Next. The sample is represented by a group of 25 students of the three-year bachelor's degree in Exercise Science from the University of Salerno, aged between 20 and 27 years. the results of the initial data confirm the impossibility of breaking down the movement into simpler parts in order to understand how it works because it emerges that the movement must be considered in its entirety. the integrated use of quantitative biomechanical and qualitative educational evaluation can be achieved with self-assessment and enabling self-esteem. In conclusion, the study can be useful for identifying the areas of performance to be analysed in order to form the physical and sport educational professional skills most dedicated to evaluation. Keywords: Self-perception; Self-evaluation; Optojump; Strength; Coordination; Complex systems.
\end{abstract}

\section{Cite this article as:}

Di Domenico, F., Fattore, S., \& D'Isanto, T. (2019). The movement: Complexity and reductionism, evidence in comparison. Journal of Human Sport and Exercise, 14(4proc), S602-S609. doi:https://doi.org/10.14198/ihse.2019.14.Proc4.18

\section{Corresponding author. University of Salerno, Italy.}

E-mail: flcdidomenico@gmail.com

Supplementary Issue: Spring Conferences of Sports Science. 15th Convention and Workshop of the International Network of Sport and Health Science, 5-8 June 2019. University of Las Palmas de Gran Canaria, Las Palmas de Gran Canaria, Spain. JOURNAL OF HUMAN SPORT \& EXERCISE ISSN 1988-5202

(c) Faculty of Education. University of Alicante doi:10.14198/jhse.2019.14.Proc4.18 


\section{INTRODUCTION}

Strength is the only capacity present in every motor gesture which, based on regulation and control mechanisms, has a different mode of expression. Muscle strength is the ability of a muscle to oppose resistance. It never occurs in pure form, but always combined in mixed forms: organic-muscular and coordinative factors (Paavo, 1991, Weineck, 2009, Boyle, 2018, D'elia et al., 2019). In the execution of the motor gesture, the body, working as a system, produces a quantity of force which, to be effective for the purposes set, must be managed and integrated by neurological structures (Ceciliani, 2019, Ceciliani, et al., 2005, Federici et al., 2019, Raiola, 2017, Raiola, Di Tore, 2017, Altavilla, 2014, Raiola, 2013, Zatsiorsky, Kraemer, 2006). We are therefore talking about extremely complex phenomena, the treatment of which can no longer be limited to simplistic classifications adopted for years following reductionist approaches (Bosch, 2015). The movement is understood as the precise chain of multiarticular actions that follow a precise order (kinetic chain) based on muscular synergies. According to Boyle's definition (2010), "movement manifests itself as a combination of posture and control of the body and its parts referring to patterns of manipulation (moving things) and locomotion (moving oneself). Movement is synonymous with function " (Tiziana, et al., 2018, Gaetano, 2016, Boyle, 2010, Gambetta, 2011). Research on human movement should adopt a holistic approach to the problem, since the subject (organism / body) in its biological structure is an open system that, interacting with the environment, learns and adapts. The concept of complex system differs from the complicated system. A complicated system can be, at least in principle, completely understood and modelled. A complex system, on the other hand, cannot be completely understood or definitively modelled. It is argued that biology and all human and social sciences deal with complex systems (Poli, 2013). The movement takes many forms, some can be considered as genetically determined, which seem to be fairly stereotyped for all members of the same species. A second class of movements is defined as "learned". These learned movements are often called skills (Schmidt, Lee, 2012). This work, based on a detailed study of scientific texts and magazines, aimed to provide a detailed description of one of the fundamental functions of man, namely movement. The key topic was the conditional abilities, no longer considered as an isolated and abstract concept, but as components of a complex process that includes elements of various nature which, working in an integrated manner, on the basis of specific self-regulation processes, contribute to the realization of the motor gesture (Zatsiorsky, Kraemer, 2006, Schmidt, Lee, 2012). The aim is to identify the elements that influence the mechanisms of force production, in its various expressions, in relation to a given motor task. These elements can be biochemical in nature, therefore linked to processes of production and use of energy, biomechanics (levers, joints, associated mechanical characteristics), neurophysiological, concerning the mechanisms of control of the nervous system in movement management. For this purpose, we will not only consider the individual capacity in its own right, but we will proceed following a "functional" approach (Gambetta, 2011). The concept of complex system differs from the complicated system. A complicated system can be, at least in principle, completely understood and modelled. A complex system, on the other hand, cannot be completely understood or definitively modelled. It is argued that biology and all human and social sciences deal with complex systems (Meraviglia, 2012, Poli, 2013).

\section{METHODS}

The realization of the study has developed through the succession of some procedures:

- Sample selection;

- Sending the online questionnaire to find data on the current and past motor-sports habits of the evaluated subject;

- Identification of the statistical units with assignment of an identification code; 
- Test execution with specific instrumentation;

- Data recording;

- Data analysis;

- Conclusions.

The tools used for the realization of this work have been carefully selected:

- Informed consent signed by the students undergoing the study;

- Questionnaire written on Google Forms administered before the actual evaluation;

- OptoJump Next instrumentation, supplied by the University;

Other accessory tools used in the tests were: chronometer, pc, cameras.

The research sample is represented by a group of students from the University of Salerno, attending the second year of the three-year degree in "Exercise and sport sciences".

In particular, we are talking about 25 students aged between 20 and 27 years. Anthropometric and personal data were collected on these subjects: age, height, weight. Furthermore, for each of them an identification code was generated consisting of five digits obtained from the last three digits of the university matriculation number and the first initial of the surname and name. These data were obtained by submitting the statistical units, after signing the informed consent, to a questionnaire prepared by the Google Forms platform.

The Google Forms platform allowed us to find qualitative and quantitative data on the previous and current motor experiences of the statistical units and, if athletes, the level of practice of the sport indicated (weekly training sessions, duration of training sessions, etc.).

After collecting this data via the Google Forms platform, we moved on to the actual test protocol using Opotojump Next instrumentation. In particular the tests used for the purpose are:

1. Counter movement jump squat with hands on hips;

2. Counter movement jump squat with free arms.

\section{Data collection and analysis Counter Movement Jump (CMJ) squat}

This test is used to measure the ability to elastically reuse the strength of the extensor muscles of the lower limbs. It is a very useful test to evaluate the ability of reactive force.

\section{Procedure}

It consists of a vertical jump, starting from the erect position, preceded by counter movement with bending of the knees up to about $90^{\circ}$ (muscle stretching-shortening cycle). The subject must place himself in the starting position keeping his feet even with the heels in contact with the ground and the erect station with the trunk vertical with respect to the ground. At the start the subject will have to make the jump upwards with the maximum intensity, making him precede by a rapid bending of the knees up to reach the $90^{\circ}$ angle, keeping the heels in contact with the ground and the erect trunk; in this way the elevation is improved thanks to the accumulation and reuse of elastic energy and to a greater reflex muscle tension. The fall must be carried out with the knees extended, on the toes with subsequent cushioning to avoid trauma. 


\section{RESULTS}

The results of the research show differences between the subjects that could be linked both to the muscle tendon and biomechanical structure and to the superior control mechanisms or, again, to the motor background possessed by subjects coming from various different experiences. The parameters detected are: Flight time and jump height. The two parameters have a proportional trend.

Table 1. CMJ test results

\begin{tabular}{|r|l|r|r|r|l|r|r|}
\hline$\#$ & A THLETE & AGE & WEIGHT & SEX & SPORT & FIGH TIME & HEIGHT \\
\hline 1 & $469 \mathrm{GI}$ & 20 & 53 & $\mathrm{~F}$ & None & 0,408 & 20,4 \\
\hline 2 & $483 \mathrm{BA}$ & 22 & 78 & $\mathrm{M}$ & Football & 0,469 & 27 \\
\hline 3 & $483 \mathrm{EG}$ & 20 & 83 & $\mathrm{M}$ & Football & 0,508 & 31,6 \\
\hline 4 & $494 \mathrm{BR}$ & 20 & 54 & $\mathrm{M}$ & Cycling & 0,535 & 35,1 \\
\hline 5 & $501 \mathrm{DV}$ & 21 & 57 & $\mathrm{~F}$ & Volleyball & 0,424 & 22 \\
\hline 6 & $512 \mathrm{PL}$ & 22 & 66 & $\mathrm{M}$ & Swim/Karate & 0,516 & 32,6 \\
\hline 7 & $530 \mathrm{DM}$ & 20 & 56 & $\mathrm{~F}$ & Dance & 0,404 & 20 \\
\hline 8 & $536 \mathrm{LS}$ & 20 & 60 & $\mathrm{~F}$ & Volleyball & 0,379 & 17,6 \\
\hline 9 & $544 \mathrm{IF}$ & 21 & 60 & $\mathrm{M}$ & Football & 0,508 & 31,6 \\
\hline 10 & $548 \mathrm{PV}$ & 24 & 75 & $\mathrm{M}$ & Boxing & 0,465 & 26,5 \\
\hline 11 & $553 \mathrm{IM}$ & 21 & 47 & $\mathrm{~F}$ & Futsal & 0,398 & 19,4 \\
\hline 12 & $560 \mathrm{PC}$ & 20 & 70 & $\mathrm{M}$ & Basket & 0,482 & 28,5 \\
\hline 13 & $562 \mathrm{NC}$ & 21 & 105 & $\mathrm{M}$ & Football & 0,446 & 24,4 \\
\hline 14 & $563 \mathrm{MF}$ & 20 & 65 & $\mathrm{~F}$ & Volleyball & 0,48 & 28,2 \\
\hline 15 & $615 \mathrm{M}$ & 20 & 65 & $\mathrm{M}$ & Soccer referee & 0,493 & 29,8 \\
\hline 16 & $624 \mathrm{FM}$ & 26 & 78 & $\mathrm{~F}$ & Body building & 0,418 & 21,4 \\
\hline 17 & $635 \mathrm{DN}$ & 20 & 62 & $\mathrm{M}$ & Football & 0,477 & 27,9 \\
\hline 18 & $639 \mathrm{CE}$ & 24 & 57 & $\mathrm{~F}$ & Volleyball & 0,458 & 25,7 \\
\hline 19 & $652 \mathrm{FA}$ & 20 & 57 & $\mathrm{M}$ & Athletics & 0,517 & 32,8 \\
\hline 20 & $656 \mathrm{MG}$ & 20 & 82 & $\mathrm{M}$ & Body building & 0,521 & 33,3 \\
\hline 21 & $786 \mathrm{MR}$ & 22 & 84 & $\mathrm{M}$ & Football & 0,457 & 25,6 \\
\hline 22 & $788 \mathrm{LA}$ & 20 & 58 & $\mathrm{~F}$ & Basket & 0,372 & 17 \\
\hline 23 & $791 \mathrm{AV}$ & 25 & 45 & $\mathrm{~F}$ & Athletics & 0,337 & 13,9 \\
\hline 24 & $798 \mathrm{GA}$ & 20 & 64 & $\mathrm{~F}$ & Rugby/Karate & 0,443 & 24,1 \\
\hline 25 & $851 \mathrm{VD}$ & 20 & 60 & $\mathrm{~F}$ & Volleyball & 0,467 & 26,7 \\
\hline & & & & AVERAGE & 0,455 & 25,7 \\
\cline { 3 - 7 } & & & & MINIMUM & $\# 23-0,337$ & $\# 23-13,9$ \\
\cline { 3 - 8 } & & & & MAXIMUM & $\# 4-0,535$ & $\# 4-35,1$ \\
\hline
\end{tabular}

\section{DISCUSSION}

The subject who achieved the best results in terms of height and flight time was 494BR, a male subject, 20 years old, $152 \mathrm{~cm}$ tall and weighing $54 \mathrm{~kg}$. This is a non-competitive level cycling athlete for 6 years. On average, 3 training sessions per week of more than two hours are practiced for this activity. Previously, from 7 years to 14 years, he practiced Kung Fu at a non-competitive level. For this sport he practiced 2 weekly training sessions. His motor experiences give us a fairly sedentary profile in the age group from 3 to 9 years, privileging as an activity "watching TV / playing video games", practicing them with a weekly frequency of 46 hours. From 10 to 13 years of age the privileged physical activity was "playground / outdoor activities" which he practiced every week for 4-6 hours. The reaction times obtained in the test were $0.557 \mathrm{sec}$ for the right 
leg and $0.807 \mathrm{sec}$ for the left leg. In this test he reached a height of $35.1 \mathrm{~cm}$ with a flight time of 0.535 seconds.

Data collection and analysis Counter Movement Jump (CMJ) squat with free arms

This test, like the previous test, allows us to evaluate the elastic-reactive force of the subject with the addition of coordinative elements. The test will thus be more useful for evaluating athletes in sports disciplines in which the intervention of the arms favours the elevation of the body.

\section{Procedure}

The subject places itself inside the perimeter delimited by the Optojump Next bars without any indication on the positioning of the arms. From when he hears the beep he must, when he is ready, make a jump as soon as he has executed a squat with free arms.

\section{RESULTS}

As in the previous test the results were very different among the subjects tested, but the addition of the variable free arms gave different results even compared to the previous test. Most of the subjects improved their performance, someone got worse.

Table 2. CMJ Squat test results with free arms

\begin{tabular}{|c|c|c|c|c|c|c|c|c|c|c|}
\hline & & & & & & CMJ FREE ARMS & & CMJ & & \\
\hline \# & ATHLETE & AGE & WEIGHT & SEX & SPORT & FIGHT TIME & HEIGHT & FIGHT TIME & HEIGHT & \\
\hline 1 & $469 \mathrm{GI}$ & 20 & 53 & $\bar{F}$ & None & 0,403 & 19,9 & $\overline{0,408}$ & 20,4 & - \\
\hline 2 & 483BA & 22 & 78 & $M$ & Football & 0,527 & 34 & 0,469 & 27 & + \\
\hline 3 & $483 \mathrm{EG}$ & 20 & 83 & $\bar{M}$ & Football & 0,439 & 23,6 & 0,508 & 31,6 & - \\
\hline 4 & 494BR & 20 & 54 & $\bar{M}$ & Cycling & 0,567 & 39,4 & 0,535 & 35,1 & + \\
\hline 5 & 501DV & 21 & 57 & $F$ & Volleyball & 0,485 & 28,8 & 0,424 & 22 & + \\
\hline 6 & $512 \mathrm{PL}$ & 22 & 66 & $M$ & Swim/Karate & 0,565 & 39,1 & 0,516 & 32,6 & + \\
\hline 7 & $530 \mathrm{DM}$ & 20 & 56 & $\mathrm{~F}$ & Dance & 0,472 & 27,3 & 0,404 & 20 & + \\
\hline 8 & $536 \mathrm{LS}$ & 20 & 60 & $\bar{F}$ & Volleyball & 0,428 & 22,5 & 0,379 & 17,6 & + \\
\hline 9 & 544IF & 21 & 60 & $M$ & Football & 0,613 & 46,1 & 0,508 & 31,6 & + \\
\hline 10 & 548PV & 24 & 75 & $M$ & Boxing & 0,473 & 27,4 & 0,465 & 26,5 & + \\
\hline 11 & 553IM & 21 & 47 & $\mathrm{~F}$ & Futsal & 0,448 & 24,6 & 0,398 & 19,4 & + \\
\hline 12 & $560 \mathrm{PC}$ & 20 & 70 & $\bar{M}$ & Basket & 0,571 & 40 & 0,482 & 28,5 & + \\
\hline 13 & $562 \mathrm{NC}$ & 21 & 105 & $M$ & Football & 0,512 & 32,1 & 0,446 & 24,4 & + \\
\hline 14 & $563 \mathrm{MF}$ & 20 & 65 & $F$ & Volleyball & 0,509 & 31,8 & 0,48 & 28,2 & + \\
\hline 15 & $615 \Pi$ & 20 & 65 & $\bar{M}$ & Soccer referee & 0,525 & 33,8 & 0,493 & 29,8 & + \\
\hline 16 & 624FM & 26 & 78 & $\mathrm{~F}$ & Body building & 0,465 & 26,5 & 0,418 & 21,4 & + \\
\hline 17 & 635DN & 20 & 62 & $M$ & Football & 0,486 & 29 & 0,477 & 27,9 & + \\
\hline 18 & 639CE & 24 & 57 & $F$ & Volleyball & 0,516 & 32,6 & 0,458 & 25,7 & + \\
\hline 19 & $652 \mathrm{FA}$ & 20 & 57 & $\bar{M}$ & Athletics & 0,573 & 40,2 & 0,517 & 32,8 & + \\
\hline 20 & 656MG & 20 & 82 & $M$ & Body building & 0,583 & 41,7 & 0,521 & 33,3 & + \\
\hline 21 & $786 \mathrm{MR}$ & 22 & 84 & $M$ & Football & 0,535 & 35,1 & 0,457 & 25,6 & + \\
\hline 22 & 788LA & 20 & 58 & $\mathrm{~F}$ & Basket & 0,382 & 17,9 & 0,372 & 17 & + \\
\hline 23 & 791AV & 25 & 45 & $\mathrm{~F}$ & Athletics & 0,401 & 19,7 & 0,337 & 13,9 & + \\
\hline 24 & $798 \mathrm{GA}$ & 20 & 64 & $\mathrm{~F}$ & Rugby/Karate & 0,467 & 26,7 & 0,443 & 24,1 & + \\
\hline 25 & 851VD & 20 & 60 & $\mathrm{~F}$ & Volleyball & 0,525 & 33,8 & 0,467 & 26,7 & + \\
\hline & & & & & AVERAGE & 0,455 & 30,9 & & & \\
\hline & & & & & MINIMUM & $\# 22-0,382$ & $\# 22-17,9$ & & & \\
\hline & & & & & MAXIMUM & $\# 9-0,613$ & $\# 9-46,1$ & & & \\
\hline
\end{tabular}




\section{DISCUSSION}

The subject who obtained the best result in this test is $544 \mathrm{IF}$, a male subject, aged $21,169 \mathrm{~cm}$ tall and weighing $60 \mathrm{~kg}$. He played soccer and kung fu. Football has been the sport practiced since he was 8 for 10 years. He trained on average 3 times a week, the sessions lasted 1-2 hours. From the age of 3 to 13 , he has always preferred to play "backyard games / outdoor activities". It is underway with university exams. In the execution of this test he reached a height of $46.1 \mathrm{~cm}$ remaining in flight for 0.613 seconds improving his performance, compared to the previous test, of $14.5 \mathrm{~cm}$ with regards to the height of the jump and 0.105 seconds as regards the flight time.

There have been athletes who have worsened their performance compared to the previous test. For example, 483EG with a height of $23.6 \mathrm{~cm}$ and a flight time of 0.439 seconds worsened its result by $8 \mathrm{~cm}$ in height and by 0.069 in terms of flight time. $483 \mathrm{EG}$ is a male subject, aged 20,185 cm tall and weighing $80 \mathrm{~kg}$. Practice football at a competitive level for 9 years. he trains on average 4 times a week for 1-2 hours per session. In the past, from 7 years 11 years old, he has practiced kick boxing at a competitive level. For this last sport, 3 sessions a week of training took place. From the age of 3 to 5 , he favoured "backyard games / outdoor activities", which he practiced every 4-6 hours a week. From the age of 6 to 13 he favoured "games in the gym" which he practiced with a frequency of 4-6 hours a week.

The subject who obtained the best result in this test is $544 \mathrm{IF}$, a male subject, aged $21,169 \mathrm{~cm}$ tall and weighing $60 \mathrm{~kg}$. He played soccer and kung fu. Football has been the sport practiced since he was 8 for 10 years. He trained on average 3 times a week, the sessions lasted $1-2$ hours. From the age of 3 to 13 , he has always preferred to play "backyard games / outdoor activities". In the execution of this test he reached a height of $46.1 \mathrm{~cm}$ remaining in flight for 0.613 seconds improving his performance, compared to the previous test, of $14.5 \mathrm{~cm}$ with regards to the height of the jump and 0.105 seconds as regards the flight time.

\section{CONCLUSION}

From the analysis of the results obtained from the test protocol it has been highlighted how various factors of various nature contribute to the realization of a gesture of any kind. Therefore, we will have subjects that, in performing a given motor task, albeit for the first time, will achieve positive results because they have learned skills in the past that they can reuse by adapting them to the task (D'elia, 2019, Forte et al., 2019, D'elia et al., 2018, Andorlini, 2015). Motor development takes place incessantly throughout life. This mechanism is due to hereditary genetic heritage, experiences and the environment (Schmidt, Lee, 2012).

Indeed, one of the aims of this research was to evaluate the efficiency, in terms of force production, of the execution of a motor gesture going to investigate the possible factors that contribute directly or indirectly to the final result, from the skills acquired in the past to motor experiences at the time of the test (Alminni et al, 2019). The data obtained gave quite clear indications on the skills and abilities that different sports tend to develop more. The data collected from the responses to the Google Forms questionnaire gave starting point for reflection on the possible causes that determine the optimal construction and execution of a given gesture. In fact, the close correlation between optimal motor learning in the sensitive phases and availability of a good number of motor patterns is confirmed, which can be adapted to specific requests (Calabrese, 2011, Andorlini, 2015).

The other purpose of this research was to evaluate how elements of a coordinative nature could influence the result of a given motor gesture (Vealey, Chase, 2016). In fact, in the cmj test with free arms we will have 
variations in the results among the subjects, which do not always occur in terms of improvement, but, on the contrary, sometimes even worse. This can occur in subjects who have not effectively refined certain motor mechanisms during motor learning (D'lsanto et al., 2019, Altavilla et al., 2018).

\section{REFERENCES}

Alminni C., Altavilla, G., Cassese, F.P., Ceciliani, A., D'isanto, T. (2019) Physical and motor tests to estimate the improvement of the float serve, Journal of Human Sport and Exercise, 14 (Proc2), pp. S245-S250. https://doi.org/10.14198/ihse.2019.14.proc2.13

Altavilla, G., D'isanto, T., Di Tore, P.A. (2018) Anthropometrics characteristics and jumping ability in basketball, Journal of Human Sport and Exercise, 13, pp. S385-S392. https://doi.org/10.14198//hse.2018.13.proc2.22

Altavilla, G. (2014) Effects of the practice of muscle stretching, Sport Science, 7 (1), pp. 66-67.

Andorlini A., (2015) Pre-correre i tempi. Dalla teoria delle idee all'esercizio dei movimenti, Strenght \& Conditioning, anno IV n. 13.

Bobath B., Bobath K., (2015) Lo sviluppo motorio nei diversi tipi di paralisi cerebrale, Sorbello.

Bompa T., Buzzichelli C. A., (2017) Periodizzazione dell'allenamento sportivo, Calzetti Mariucci, PG.

Bosch F, Cook K., (2015) Strength training and coordination: an integrative approach, Uitgevers.

Boyle M., Allenamento funzionale applicato allo sport, Olympians, Firenze, 2018.

Brown L. E., Ferrigno V., (2005) Training for Speed, Agility, and Quickness, Human Kinetics, UK.

Calabrese L., (2011) L'apprendimento motorio tra i cinque e i dieci anni, Editore Armando, Roma.

Caselli M., (2005) Indagare col questionario: introduzione alla ricerca sociale di tipo standard, Vita e pensiero, Milano.

Ceciliani, A. (2018)From the embodied cognition to the embodied education in the physical and sports sciences, Encyclopaideia, 22 (51), pp. 11-24.

Ceciliani, A., Di Carlo, M., Tentoni, C. (2005) Mental process learning Medicina dello Sport, 58 (1), pp. 43-52.

D‘Elia, F. (2019). The training of physical education teacher in primary school. Journal of Human Sport and Exercise, 14(1proc), S100-S104. https://doi.org/10.14198/ihse.2019.14.Proc1.12

D'Elia, F., D'Isanto, T., \& Altavilla, G. (2019). Training and performance in the transition period. Journal of Human Sport and Exercise, 14(2proc), S258-S262. https://doi.org/10.14198/ihse.2019.14.Proc2.15

D'Elia, F., Mazzeo, F., \& Raiola, G. (2018). The core curriculum in the university training of the teacher of physical education in Italy. Journal of Human Sport and Exercise, 13(2proc), S413-S420. https://doi.org/10.14198/ihse.2018.13.Proc2.25

D'Isanto, T., D'Elia, F., Raiola, G., Altavilla, G. (2019) Assessment of sport performance: Theoretical aspects and practical indications, Sport Mont, 17 (1), pp. 79-82.

Federici, A., Zumbo, F., Raiola, G. (2019) Use of chains as a means of intensifying the load in resistance training, Journal of Physical Education and Sport, 19, art. no. 68, pp. 466-472.

Forte, D., Ceciliani, A., Izzo, R., Altavilla, G. (2019) Transition period: Pilot study on performance reduction of ability to jump in volleyball, Journal of Human Sport and Exercise, 14 (Proc2), pp. S221 S227. https://doi.org/10.14198/ihse.2019.14.proc2.09

Gaetano, A. (2016) Relationship between physical inactivity and effects on individual health status, Journal of Physical Education and Sport, 16, pp. 1069-1074.

Gambetta V., (2011) Following The Functional Path, Momentum Media Sports, USA.

Meraviglia V., (2012) Sistemi motori: Nuovi paradigmi di apprendimento e comunicazione, SpringerVerlag, Milano. https://doi.org/10.1007/978-88-470-1995-9 7 
Weineck J., (2009) L'allenamento ottimale, Calzetti Mariucci, Perugia.

Paavo K., (1991) Strenght and power in sport, Blackwell Science Ltd USA.

Raiola, G. (2017) Motor learning and teaching method, Journal of Physical Education and Sport, 17, art. no. 236, pp. 2239-2243.

Raiola, G., Di Tore, P.A. (2017) Motor learning in sports science: Different theoretical frameworks for different teaching methods, Sport Science, 10, pp. 50-56.

Raiola, G. (2013) Body knowledge and motor skills, Knowledge Cultures, 1 (6), pp. 64-72.

Schmidt R., Lee T., (2012) Controllo motorio e apprendimento, Calzetti Mariucci, PG.

Tiziana, D., Antonetta, M., Gaetano, A. (2017) Health and physical activity, Sport Science, 10 (1), pp. 100-105.

Vealey R. S., Chase M. A., (2016) Best Practice for Youth Sport, Human Kinetics, UK.

Zatsiorsky, V. M., \& Kraemer, W. J. (2006). Science and practice of strength training. Champaign, IL: Human Kinetics. 